\title{
Association of Serum Iron and Ferritin Levels in Patients of Cholelithiasis: A Cross-Sectional Study
}

\author{
Madhukar Rajaram Wagh ${ }^{\odot}$, Sunil Joshi ${ }^{\odot}$ \\ Assistant Professor, Department of Surgery, Banas Medical College and Research Institute, Palanpur, Gujarat, India.
}

\section{Abstract}

Background: Cholelithiasis is a common abdominal disorder resulting in increasing hospital admissions. About 10-12\% of adults develop gallstones. Aim of this study was to find out any association of serum iron and ferritin levels in patients of cholelithiasis. Subjects and Methods: Present study was conducted at the department of surgery, tertiary care institute of for the period 1 year. For the study purpose 70 gall stone cases and 70 normal healthy matched controls were taken as study participants. After explaining about the study to the subjects, an informed consent will be obtained, followed by a detailed history with clinical examination with more emphasis on the parameters given below in outcome variable (ultrasonography finding, serum iron level, serum ferritin level, serum cholesterol). Results: The mean age in the case group (gallstones present) is 43.12 years, as compared to the control group the mean age is 41.05 years, The study shows in the case group $64 \%$ of patient was female and $36 \%$ was male and in the control group $76 \%$ of patient was female and $24 \%$ was male. In this study 46 (65.7\%) patients with gallstones have the value of serum iron less than normal (normal value: $>40 \mu \mathrm{g} / \mathrm{dl}$ ). Our study shows, there are 35 female patients with gallstone disease who have serum iron levels below the normal value Most of the patients with gallstone disease whose serum iron levels are subnormal are females. Our study shows that the mean serum iron between cases and control was statistically significant $p \leq 0.05$. There is no effect of anemia on serum cholesterol. In this study the mean serum cholesterol between cases and control was statistical insignificant ( $>0.7)$ ) In the case group, 20 of male and 36 of female patients have normal serum ferritin levels. The number of females having normal serum ferritin levels (in both case and control groups) is more. Conclusion: Gallstones are more prevalent in female population than males. Serum ferritin association is insignificant as it increases other condition with inflammation also. Low serum iron level associated with high risk of cholelithiasis as this may lead to super saturation of bile.

Keywords: Bile, Cholelithiasis, Serum cholesterol, Serum ferritin

Corresponding Author: Sunil Joshi, Assistant Professor, Department of Surgery, Banas Medical College and Research Institute, Palanpur, Gujarat, India.

E-mail: drsuniljoshipal12@gmail.com

Received: 14 December 2019

Revised: 21 January 2020

Accepted: 26 January 2020

Published: 26 May 2020

\section{Introduction}

Calculous biliary disease by far, the most common pathology involving the gallbladder (GB) and biliary India tree. ${ }^{[1-3]}$ GB concentrates bile; however, the concentration of solutes in the GB differs from that in the rest of the biliary tree. This increase in solute concentration combined with stasis in the GB between meals predisposes to stone formation in the gallbladder. ${ }^{[4]}$ Cholelithiasis is a common abdominal disorder resulting in increasing hospital admissions. About $10-12 \%$ of adults develop gallstones. ${ }^{[5]}$ The prevalence of common bile duct stones in patients with gallstones varies from 8 to $16 \%{ }^{[6]}$ Pure cholesterol stones are uncommon and account for less than $10 \%$ of all stones. Whether pure or of mix nature, the common primary event in the formation of cholesterol stone is super saturation of bile with cholesterol. Super saturation almost always is caused by cholesterol hyper secretion rather than reduced secretion of phospholipids or bile salts. The basic pathophysiology of GS formation is a complex interplay of supersaturation of secreted bile, ${ }^{[7,8]}$ concentration of bile in the gallbladder, crystal nucleation, and GB dysmotility. Thus, high concentrations of cholesterol and lipid in bile secretions from the liver predispose to cholesterol stone formation, whereas increased hemoglobin catabolism leads to pigment stone formation.

In pigment stone formation mainly, infection plays role. Ideally biliary tract infection should be defined by organism count in bile. Therefore 105 organisms $/ \mathrm{ml}$ in over $90 \%$ of peroperative bile culture is taken as diagnostic. ${ }^{[9,10]}$ 
The presentation may range from flatulent dyspepsia and acute cholecystitis to its complications like empyema, chronic cholecystitis, gangrene, fistula and gallbladder carcinoma. ${ }^{[11]}$ Today, the incidence of gallstone disease has increased considerably due to frequent use of ultrasonography. ${ }^{[12]}$ Recent studies have defined the role of trace elements $(\mathrm{Fe}$, Calcium, $\mathrm{Zn}$ and $\mathrm{Cu}$ ) and defective $\mathrm{pH}$ in the formation of gall stones. ${ }^{[5]}$

The aim of this study was to find out any association of serum iron and ferritin levels in patients of cholelithiasis.

\section{Subjects and Methods}

Present study was conducted at the department of surgery, tertiary care institute of for the period 1 year. Sample size was calculated on the basis of alpha error 0.05 and power $80 \%$ assuming proportion of subjects with iron level less than normal range in gall stone cases and control. So, for the study purpose 70 gall stone cases and 70 normal healthy matched controls were taken.

\section{Inclusion Criteria}

All patients suffering from cholelithiasis confirmed by ultrasonography were included in this study and willing to participate in the study.

\section{Exclusion Criteria}

Patients not willing to participate and having following disorders/disease were not included: Hematological disorders, cirrhosis of liver and pregnant females.

Seventy patients each were divided into cases and controls

\section{Cases}

Patients with ultrasonographically proven gall stone and meeting inclusion and exclusion criteria named as Group A.

\section{Control}

Matched control will be taken for study. Apparently healthy individual without cholelithiasis will be the control named as Group B.

After explaining about the study to the subjects, an informed consent will be obtained, followed by a detailed history with clinical examination with more emphasis on the parameters given below in outcome variable (ultrasonography finding, serum iron level, serum ferritin level, serum cholesterol).

\section{Statistical analysis}

The recorded data was compiled and entered in a spreadsheet computer program (Microsoft Excel 2007) and then exported to data editor page of SPSS version 15 (SPSS Inc., Chicago, Illinois, USA). Descriptive statistics included computation of percentages, means and standard deviations. For all tests, confidence level and level of significance were set at $95 \%$ and $5 \%$ respectively.

\section{Results}

The mean age in the case group (gallstones present) is 43.12 years, as compared to the control group the mean age is 41.05 years, Both groups are comparable as far as age distribution is considered [Table 1]. The study shows in the case group 64\% of patient was female and $36 \%$ was male and in the control group $76 \%$ of patient was female and $24 \%$ was male [Table 2].

In this study 46 (65.7\%) patients with gallstones have the value of serum iron less than normal (normal value: $>40 \mu \mathrm{g} / \mathrm{dl}$ ), 16 patients in the case group whose value is less than normal are anemic, 19 of the healthy volunteers have value of serum iron less than normal, 5 of the healthy volunteers who have value of serum iron less than normal are anemic [Table 3].

Our study shows, there are 35 female patients with gallstone disease who have serum iron levels below the normal value, 14 females in the healthy volunteer group whose serum iron levels are below normal, only 7 female patients with gallstones whose serum iron levels are normal which is 35 females in the healthy control group. Most of the patients with gallstone disease whose serum iron levels are subnormal are females. Our study shows that the mean serum iron between cases and control was statistically significant $p \leq 0.05$.

In this study, 16 of anaemic and 30 of non-anaemic patients with gallstones have normal serum cholesterol levels, which are 12 and 34 in normal healthy individuals, respectively. 7 of anaemic and 17 of non-anaemic patients with gallstones have more than normal serum cholesterol level which is 7 and 17 in normal healthy individuals, respectively. There is no effect of anemia on serum cholesterol (Table 4). This study shows, 15 of male and 34 of female patients with gallstones have normal serum cholesterol levels, which is 14 and 36 in normal healthy individuals, respectively. 12 of male and 9 of female patients with gallstones have more than normal serum cholesterol levels, which are 4 and 15 in normal healthy individuals, respectively. Serum cholesterol has no effect on sex in the formation of gallstones.

In this study the mean serum cholesterol between cases and control was statistical insignificant ( $p>0.7)$ In this study, 57 $(82.8 \%)$ of patients with gallstones have normal value of serum ferritin; in this 20 are anemic whereas 60 in the control group have normal value and anemic are only 18 . In both group patients with gallstones most of them are non-anemic.

This study shows, in the case group, $0 \%$ of male and 3 of female patients have less than normal serum ferritin levels. This is $0 \%$ and 3 in the control group. In the case group, 20 of male and 36 of female patients have normal serum ferritin levels. This is 18 and 44, respectively, in the control group. In the case group, 7 of male and 4 of female patients have more than normal serum ferritin levels. This is 0 and 4 , respectively, 


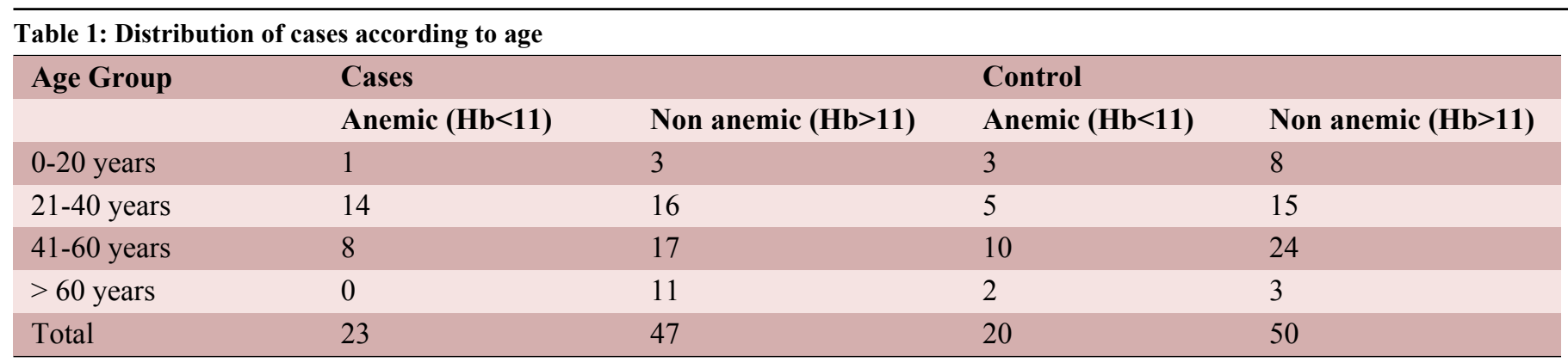

\begin{tabular}{|lllll|}
\hline Table 2: Distribution of cases according to Gender & & & \\
\hline Gender & Group A & & Group B & \\
& Number & Percentage(\%) & Number & Percentage(\%) \\
Male & 28 & 40 & 20 & 28.5 \\
Female & 42 & 60 & 50 & 71.4 \\
Total & 70 & 100 & 70 & 100 \\
\hline
\end{tabular}

\begin{tabular}{|c|c|c|c|c|c|}
\hline \multirow[t]{2}{*}{ Serum iron } & \multicolumn{3}{|l|}{ Group A } & \multicolumn{2}{|l|}{ Group B } \\
\hline & Anaemic $(\mathrm{Hb}<11)$ & $\begin{array}{l}\text { Non } \\
(\mathrm{Hb}>11)\end{array}$ & anaemic & Anaemic $(\mathrm{Hb}<11)$ & $\begin{array}{l}\text { Non } \\
(\mathrm{Hb}>11)\end{array}$ \\
\hline$<$ Normal & 16 & 30 & & 5 & 14 \\
\hline Normal $(>40)$ & 7 & 17 & & 16 & 35 \\
\hline
\end{tabular}

\begin{tabular}{|c|c|c|c|c|c|}
\hline \multirow[t]{2}{*}{ Cholesterol } & \multicolumn{3}{|l|}{ Group A } & \multicolumn{2}{|l|}{ Group B } \\
\hline & Anaemic $(\mathrm{Hb}<11)$ & $\begin{array}{l}\text { Non } \\
(\mathrm{Hb}>11)\end{array}$ & anaemic & Anaemic $(\mathrm{Hb}<11)$ & $\begin{array}{l}\text { Non } \\
(\mathrm{Hb}>11)\end{array}$ \\
\hline Normal $(<200)$ & 16 & 30 & & 12 & 34 \\
\hline$>$ Normal $(>200)$ & 7 & 17 & & 7 & 17 \\
\hline
\end{tabular}

\begin{tabular}{|c|c|c|c|c|c|c|}
\hline \multirow[t]{2}{*}{ Cholesterol } & \multicolumn{3}{|l|}{ Group A } & \multicolumn{3}{|l|}{ Group B } \\
\hline & Anaemic $(\mathrm{Hb}<11)$ & $\begin{array}{l}\text { Non } \\
(\mathrm{Hb}>11)\end{array}$ & anaemic & Anaemic $(\mathrm{Hb}<11)$ & $\begin{array}{l}\text { Non } \\
(\mathbf{H b}>11)\end{array}$ & anaemic \\
\hline$<$ Normal & 16 & 30 & & 12 & 34 & \\
\hline Normal & 20 & 38 & & 18 & 42 & \\
\hline
\end{tabular}


in the control group. The number of females having normal serum ferritin levels (in both case and control groups) is more.

\section{Discussion}

Iron deficiency has been shown to alter the activity of several hepatic enzymes, leading to increased gall bladder's bile cholesterol saturation and promotion of cholesterol crystal formation. Iron acts as a coenzyme for nitric oxide synthetase (NOS), and that is important for the maintenance of basal gall bladder tone and normal relaxation. ${ }^{[13]}$ It was found that iron deficiency resulted in altered motility of gall bladder and sphincter of Oddi, leading to biliary stasis and thus increased cholesterol crystal formation in the gall bladder bile. ${ }^{[14]}$ Hence, iron seems to play a significant role in gallstone pathogenesis. Therefore, regulation of serum iron by ferritin needs to be studied; as ferritin is the most specific marker for iron levels in the body.

At the genetic level the expression of genes controlling ferritin levels viz Iron regulatory protein (IRP-1) might play a significant role in pathogenesis of cholelithiasis. Body ferritin levels, in contrast to haemoglobin, are not affected by residential elevation above sea level or smoking behavior. ${ }^{[15]}$ Therefore, ferritin can more closely reflect relationship with iron deficiency and can be its more specific indicator, thus enabling to assess the relation between gall bladder stone and iron deficiency anaemia.

There was definite clustering of cases around 4th and 5th decade as evident from data. The $8(16 \%)$ patients out of the whole study group presented in their 6th decade whereas 11 (22\%) belonged to 3rd decade. There were 7 (14\%) patients who had age more than 60 years at the time of presentation with eldest being 66 years and only $2(4 \%)$ patient falling into $2^{\text {nd }}$ decade with age of 19 years each. These findings were similar to those observed in epidemiological study of cholelithiasis. ${ }^{[16]}$

The prevalence of gallstone disease was much more in females as compared to males with $32(64 \%)$ patients out of the total 50 being females and the rest $18(36 \%)$ were male. This is in accordance with the previous studies which stated a high prevalence of cholelithiasis in females which may be due to the effects of estrogen and progesterone on the biliary tract. Estrogenic influences increase the effect of hepatic lipoprotein receptors and stimulate hepatic hydroxyl methyl glutaryl coenzyme A (HMG Co-A) reductase activity. Consequently, together cholesterol uptake and biosynthesis are increased leading to super-saturation of bile with cholesterol and helping in formation of gallstones.

Pregnancy favors the formation of gallstones through the hormonal influence on bile composition. Estrogen induces an increased input to the hepatic free cholesterol pool by up regulating the low density lipoprotein. Decreased gallbladder motility during third trimester of pregnancy and an altered function of gallbladder mucosa that may favor nucleation and growth of stones. ${ }^{[16]}$ While studying the pathogenesis of gallstone formation, certain known risk factors can be enlisted like elderly age, female sex, obesity and rapid weight loss, cirrhosis and different diet linked issues. On seeking for other risk factors, latest studies have defined the role of trace elements like iron and calcium which might play a definitive role in the formation of gallstones. Iron deficiency alters the activity of several hepatic enzymes, leading to increased gallbladder bile cholesterol saturation and promotion of cholesterol crystal formation. ${ }^{[17]}$ It is also suggested that iron deficiency alters the activity of several hepatic enzymes. ${ }^{[18]}$ They concluded that consumption of diet rich in carbohydrates but deficient in iron altering hepatic metabolism of cholesterol that might be important in gallstone formation.

On examination of group $\mathrm{C}$ and group $\mathrm{N}$ patients, it can be concluded that the occurrence of gall stones had greater predilection for iron deficient patients as compared to patients with normal serum iron. In group C, $72 \%$ of the patient had serum iron level below normal range whereas $28 \%$ had serum iron level normal. This was $20 \%$ and $80 \%$ respectively in group $\mathrm{N}$.

A study showed $78 \%$ of patient had iron deficiency whereas $22 \%$ had normal serum iron level in patients with cholelithiasis. In control group it was $56 \%$ and $54 \%$ respectively. These findings were in accordance to literature. ${ }^{[19-21]}$ Researchers have concluded that iron deficiency led to gall bladder stasis thus, causing increased cholesterol crystal formation in bile within the gall bladder. ${ }^{[22,23]}$

In our study $72 \%$ patient in each group had normal cholesterol level whereas $28 \%$ in each group had serum cholesterol level more than normal. In the study conducted by Prasad et al and Akhtar et al $96 \%$ of patient with cholelithiasis and $98 \%$ in control group had serum cholesterol normal or less than normal. ${ }^{[24]}$ Kshirsagar et al showed $95 \%$ of patient with cholelithiasis and $98 \%$ in control group had serum cholesterol normal or less than normal. ${ }^{[25]}$

In our study $90 \%$ of patient with gallstones had serum ferritin normal or less than normal while it was $96 \%$ in the control group. In 1987, Farida Agha et al conducted a study to estimate the serum ferritin levels in normal individuals using radioimmunoassay techniques. ${ }^{[26]}$ They concluded that serum iron levels are low in gall stone patients it is expected that serum ferritin levels will also be on lower side. Ferritin levels are lower in female population and the demography of gall stone disease suggests that it is more prevalent in female population. So, serum ferritin and its regulation by iron regulator protein, understandably, will affect gall stone formation. ${ }^{[26]}$ 
Our study has a limitation of small sample size so a study with larger sample size is required to establish the role of iron deficiency in patient with cholelithiasis.

\section{Conclusion}

Gallstones are more prevalent in female population than males. Serum ferritin association is insignificant as it increases other condition with inflammation also. Low serum iron level associated with high risk of cholelithiasis as this may lead to super saturation of bile. It is that every patient with gallstones above 30 years should be screened for serum iron, serum ferritin may be used as marker of iron store so that low serum iron status could be diagnosed at early stage and progression to severe iron deficiency can be prevented.

\section{References}

1. Halldestam I, Kullman E, Borch K. Incidence of and potential risk factors for gallstone disease in a general population sample. Br J Surg. 2009;96(11):1315-1322. Available from: https: //dx.doi.org/10.1002/bjs.6687. doi:10.1002/bjs.6687.

2. Strasberg SM, Clavien PA, Harvey PRC. Pathogenesis of Cholesterol Gallstones. HPB Surg. 1991;3(2):79102. Available from: https://dx.doi.org/10.1155/1991/61741. doi:10.1155/1991/61741.

3. Bates $\mathrm{T}$, Harrison M, Lowe D, Lawson C, Padley N. Longitudinal study of gall stone prevalence at necropsy. Gut. 1992;33(1):103-107. Available from: https://dx.doi.org/10. 1136/gut.33.1.103. doi:10.1136/gut.33.1.103.

4. Holzbach RT, Marsh M, Olszewski M, Holan K. Cholesterol Solubility in Bile. Evidence that Supersaturated Bile is Frequent in Healthy Man. J Clin Invest. 1973;52(6):14671479. Available from: https://dx.doi.org/10.1172/jci107321. doi:10.1172/jci107321.

5. Diehl AK. Epidemiology and natural history of gall stone disease. Gastroenterol Clin North Am. 1991;20:1-19.

6. Kratzer W, Mason RA, Kchele V. Prevalence of gallstones in sonographic surveys worldwide. J Clin Ultrasound. 1999;27(1):1-7. Available from: https://dx.doi.org/10.1002/(sici)1097-0096(199901)27:

$1<1:$ aid-jcu1>3.0.co;2-h. doi:10.1002/(sici)10970096(199901)27:1<1::aid-jcu1>3.0.co;2-h.

7. Holan KR, Holzbach RT, Hermann RE, Cooperman AM, Claffey WJ. Nucleation time: A key factor in the pathogenesis of cholesterol gallstone disease. Gastroenterol. 1979;77(4):611-617. Available from: $\quad$ https://dx.doi.org/10.1016/0016-5085(79)90209-9. doi:10.1016/0016-5085(79)90209-9.

8. Gollish SH, Burnstein MJ, Ilson RG, Petrunka CN, Strasberg SM. Nucleation of cholesterol monohydrate crystals from hepatic and gall-bladder bile of patients with cholesterol gall stones. Gut. 1983;24(9):836-844. Available from: https://dx. doi.org/10.1136/gut.24.9.836. doi:10.1136/gut.24.9.836.

9. Anderson RE, Priestley JT. observation of the bacteriology of bile. Ann Surg. 1951;133(4):486-495.
10. Brook I. Aerobic and anaerobic microbiology of biliary tract disease. J Clin Microbiol. 1989;27(10):23732375. Available from: https://dx.doi.org/10.1128/jcm.27.10. 2373-2375.1989. doi:10.1128/jcm.27.10.2373-2375.1989.

11. Everhart JE, Gallstones. Digestive Diseases in the United States: Epidemiology and Impact . 1994;154(3):647-690. doi:10.1016/0016-5085(95)90479-4.

12. Shehadi WH. The biliary system through the ages. Int Surg. 1979;64(6):63-78.

13. Swartz-Basile DA, Goldblatt MI, Blaser C, Decker PA, Ahrendt SA, Sarna SK, et al. Iron Deficiency Diminishes Gallbladder Neuronal Nitric Oxide Synthase. J Surg Res. 2000;90(1):2631. Available from: https://dx.doi.org/10.1006/jsre.2000.5827. doi:10.1006/jsre.2000.5827.

14. Goldblatt MI, Swartz-Basile DA, Choi SH, Rafiee P, Nakeeb A, Sarna SK, et al. Iron Deficiency Transiently Suppresses Biliary Neuronal Nitric Oxide Synthase. J Surg Res. 2001;98(2):123128. Available from: https://dx.doi.org/10.1006/jsre.2001. 6196. doi:10.1006/jsre.2001.6196.

15. Cairo G, Recalcati S. Iron-regulatory proteins: molecular biology and pathophysiological implications. Expert Reviews Mol Med. 2007;9(33):1-13. Available from: https://dx.doi.org/10. 1017/s1462399407000531. doi:10.1017/s1462399407000531.

16. Acalovschi M. Cholesterol gallstones: from epidemiology to prevention. Postgraduate Med J. 2001;77(906):221229. Available from: https://dx.doi.org/10.1136/pmj.77.906. 221. doi:10.1136/pmj.77.906.221.

17. Kumar M, Goyal BB, Mahajan M, Singh S. Role of iron deficiency in the formation of gall stones. Indian J Surg. 2006;68:80-83.

18. Roslyn JJ, Conter RL, Julian E, Abedin MZ. The role of dietary iron in pigment gallstone formation. Surg. 1987;102(2):327360.

19. Kumar M, Goyal BB, Mahajan M, Singh S. Role of iron deficiency in the formation of gall stones. Indian J Surg. 2006;68:80-83.

20. Roslyn JJ, Conter RL, Julian E, Abedin MZ. The role of dietary iron in pigment gallstone formation. Surg. 1987;102(2):327360 .

21. Johnston SM, Murray KP, Martin SA, Fox-Talbot K, Lipsett $\mathrm{PA}$, Lillemoe $\mathrm{KD}$, et al. Iron deficiency enhances cholesterol gallstone formation. Surg. 1997;122(2):354-362. Available from: https://dx.doi.org/10.1016/s0039-6060(97)90027-1. doi:10.1016/s0039-6060(97)90027-1.

22. Swartz-Basile DA, Goldblatt MI, Blaser C, Decker PA, Ahrendt SA, Sarna SK, et al. Iron Deficiency Diminishes Gallbladder Neuronal Nitric Oxide Synthase. J Surg Res. 2000;90(1):2631. Available from: https://dx.doi.org/10.1006/jsre.2000.5827. doi:10.1006/jsre.2000.5827.

23. Goldblatt MI, Swartz-Basile DA, Choi SH, Rafiee P, Nakeeb A, Sarna SK, et al. Iron Deficiency Transiently Suppresses Biliary Neuronal Nitric Oxide Synthase. J Surg Res. 2001;98(2):123128. Available from: https://dx.doi.org/10.1006/jsre.2001. 6196. doi:10.1006/jsre.2001.6196.

24. Prasad PC, Gupta S, Kaushik N. To study serum iron levels in patients of gall bladder stone disease and to compare with healthy individuals. Indian J Surg. 2015;77(1):19-22. 
25. Y KA, Varadraj KM, Mahesh R, Shruti P, kumar Ujwal, Aditya P. A Study to Correlate Low Serum Iron Levels with Gallstones. J Evol Med Dent Sci. 2015;4(104):16912-16914. Available from: https://dx.doi.org/10.14260/jemds/2015/2546. doi:10.14260/jemds/2015/2546.

26. Agha F, Akhter P, Khan RA. Serum ferritin levels in apparently healthy subjects. J Pak Med Assoc. 1987;37(3):63-69.

Copyright: (C) the author(s), 2020. It is an open-access article distributed under the terms of the Creative Commons Attribution License (CC BY 4.0), which permits authors to retain ownership of the copyright for their content, and allow anyone to download, reuse, reprint, modify, distribute and/or copy the content as long as the original authors and source are cited.

How to cite this article: Wagh MR, Joshi S. Association of Serum Iron and Ferritin Levels in Patients of Cholelithiasis: A Cross-Sectional Study. Acad. J Surg. 2020;3(1):42-47.

DOI: dx.doi.org/10.47008/ajs/2020.3.1.9

Source of Support: Nil, Conflict of Interest: None declared. 